\title{
Body Mass Index and Body Fat Percent of Adult Women in Kochi, Kerala
}

\author{
Betty Rani Isaac ${ }^{1 *}$ and Usha Chandrasekhar ${ }^{2}$ \\ ${ }^{1}$ Associate Professor, St. Teresa's College, Ernakulam, Kerala, India; bettyranijose@yahoo.com \\ ${ }^{2}$ Former Dean and Head, Department of Food Science and Nutrition, Avinashilingam University, Coimbatore, Tamil \\ Nadu, India
}

\begin{abstract}
Though Kerala has registered a significant improvement in key health care indicators, the health situation in the state reflects a paradox. Being a state in developmental transition, Kerala faces the double burden of pre-transition diseases like under nutrition and infectious diseases as well as post transition chronic degenerative diseases associated with overweight and obesity. In Kerala the prevalence of overweight and obesity has increased many folds in the past few decades. The substantial proportion of underweight persons together with continuing high overall levels of overweight and obese persons produce dual burden of nutritional disorders for the state. The objective of the study was to elicit information on Body Mass Index (BMI), skin fold thickness and body fat percent of adult Women of Kochi, in Kerala. Adult (18-60 years), non pregnant and non lactating women from Kochi corporation area in Ernakulam district of Kerala was selected for the conduct of the present study. Kochi Corporation is divided into 72 wards comprising Urban, Rural, Coastal and Unclassified wards out of which 25 wards were selected as study locations to represent the corporation. A total of 1288 adult women were selected as study sample. BMI classification of WHO, was followed to categorise the sub sample for the in-depth study on the body composition pattern in relation to different BMI. Only 55.4 per cent of women were found to have normal weight (BMI between 18.5-24.9). Among subjects studied there was a higher percentage overweight/obese category than underweight. All the four skin fold measurements of the subjects showed a steep rise as per increase in BMI. Subjects had a higher skin fold in the late adult hood (30-60 yrs) compared to early adulthood. There was a direct proportion between BMI and per cent body fat; at higher BMI per cent body fat was also high.
\end{abstract}

Keywords: Body Fat Percent (BFP), Body Mass Index (BMI), Normal Height, Overweight, Underweight_ Skin Folds.

\section{Introduction}

Being a country in developmental transition, India faces the double burden of pre-transition diseases like under nutrition and infectious diseases as well as post transition chronic degenerative diseases associated with overweight and obesity. According to the recent reports in Kerala the proportion of overweight or obese women exceeded that of underweight or thinness. It is also found that the difference between men and women is more marked in Kerala. Ajithkumar and Radhadevi [1], report ed that in 1998-99 the overweight women in Kerala was 17 percent which increased to 28 per cent in 2005-06. Obesity is known to create health problems which need to get the attention of health officials making policies and plans for the future. Measurement of body composition is proving increasingly important in clinical nutrition and research. As prescribed by WHO [2] analysis of body composition confirmed that there are obvious differences in the relationship between BMI and the percentage of body fat across ethnic groups. The relative percentage of body fat at different BMI within populations. Therefore the present study was undertaken to determine the Body Mass Index and Body Composition pattern of adult women in Kochi.

*Author for correspondence 


\section{Methodology}

The state of Kerala is divided into 14 districts. The Ernakulam districtincludes the largest metropolitan region of the state and is known as the commercial capital of Kerala. Kochi corporation in Ernakulam district was selected for the conduct of the present study. It is the most densely populated corporation in the state. Kochi corporation is divided into 72 wards comprising Urban, Rural,Coastal and Unclassified wards out of which 25 wards were selected as study locations to represent the corporation. A total of 1288 adult women were selected as study sample.

In this cross sectional study, multistage stratified random sampling procedure was adopted. Of the 72 wards in the study locale, 25 wards were selected by area sampling technique. They were screened for height and weight and the BMI of each subject was calculated. BMI classification of WHO [2], was followed to categorise the subjects.

For the in-depth study on the body composition pattern of adult women in relation to different BMI, purposive sampling technique was used. A total of 210 adult women were chosen as shown in Table 1 , with equal representation by age group i.e. early adulthood 18-29 years and late adulthood 30-60 years as classified by ICMR [3] and BMI categories i.e. <18.5 (Underweight), 18.524.9 (Normal weight) and 25 and above (Overweight).

Table 1. Sample chosen for in-depth study $(\mathrm{N}=210)$

\begin{tabular}{|c|c|c|c|c|}
\hline $\begin{array}{l}\text { Age in } \\
<\text { years }\end{array}$ & Underweight & Normal weight & Overweight & Total \\
\hline $18-29$ & 35 & 35 & 35 & 105 \\
\hline $30-60$ & 35 & 35 & 35 & 105 \\
\hline Total & 70 & 70 & 70 & 210 \\
\hline
\end{tabular}

Height and weight were collected by the investigator through visits at each household individually and BMI was calculated from the data on height and weight. For the in-depth study, on body composition pattern of 210 adult women reselected from the study locale, apart from height and weight, circumference at mid upper arm and skinfold thickness at biceps, triceps, subscapula and suprailiac were also taken. Body fat percent was determined using the sum of skinfold measurements [4].
Perhaps one of the most frequently used equations for determining body fat composition is the equation of Durnin and Womersley [4].

Skinfold thickness was measured to the nearest millimetres $(\mathrm{mm})$. These readings were made at four sites on all subjects, i.e. biceps, triceps, subscapular and suprailiac areas. Body fat equivalent to sum of skinfold thickness was calculated by Durnin and Womersley Table [4].

Multistage sampling was adopted for the present study. Data were entered and statistically analysed using SPSS version 17. All the entries were double checked for any possible key board error. For both anthropometric and body composition parameters, the distribution was confirmed for mean and standard deviation. The data thus obtained were tabulated, analyzed and interpreted.

\section{Results and Discussion}

\subsection{General Characteristics of the Selected}

\section{Subjects}

A total of 1288 adult subjects selected randomly from 25 wards of Kochi corporation area were included for this study. The age group was classified as young adults (18-29 years) and elder adults (30-60 years). The data obtained related to the general characteristics of the study population is summarised in Table 2.

Table 2. General characteristics of the selected adults

\begin{tabular}{|c|c|c|}
\hline Particulars & Frequency & Percentage \\
\hline \multicolumn{3}{|l|}{ Age (years) } \\
\hline $18-29$ & 530 & 41.1 \\
\hline $30-60$ & 758 & 58.9 \\
\hline \multicolumn{3}{|l|}{ Religion } \\
\hline Hindus & 626 & 48.6 \\
\hline Christians & 493 & 38.3 \\
\hline Muslims & 169 & 13.1 \\
\hline \multicolumn{3}{|l|}{ Educational qualification } \\
\hline$<$ S.S.L.C & 59 & 4.6 \\
\hline S.S.L.C \&P.D.C & 216 & 6.8 \\
\hline Graduate & 497 & 38.6 \\
\hline Post Graduate & 516 & 40.1 \\
\hline Total & 1288 & 100 \\
\hline
\end{tabular}


Age distribution shows that 41.1 per cent belonged to the category of younger adults (18-29 years) and 58.9 per cent were older adults (30-60years). A trend projection study on age structure of Kochi Corporation conducted by Department of Statistics in Cochin University of Science and Technology revealed that youth and middle aged population consist of a major portion of the total population in Kochi corporation by 2006 [5].

Hindus, Christians and Muslims are the major communities of the state. As per census of the Kerala state [5], of the total population, $56.2 \%$ were Hindus, $24.7 \%$ wereMuslims and 19\% were Christians. Data from the present study of Kochi Corporation also showed the preponderance of Hindu population (48.6\%) followed by Christian (38.3\%) and Muslim (13.1\%). Kerala has a unique record in India for the harmonious co-existence of diverse religions.

Regarding educational level, majority were well educated i.e. 38.6 per cent were graduates, 40.1 per cent were post graduates. Only 4.6 per cent had education below SSLC and none of the subjects were illiterates. This distribution on educational level is in accordance with the findings of www.corporation of cochin.net that there is only a negligible percentage of the population in Kochi Corporation is illiterate. According to NFHS-2 [6] reports, Kerala has one of the highest literacy rates in the country. Ninety-three per cent of males and 85 per cent of females between age six and above are literate; an increase of 3 percentage points each is seen in the literacy rates of males and females since the time of NFHS-1 [7]

Table 3 shows the Body Mass Index of the selected subjects Out of the 1288 adult women studied only 55.4 per cent had normal weight (BMI 18.5 - 24.9). Body Mass Index data shows that prevalence of underweight (BMI $<18.5)$ was 11.6 per cent among female. Severe thinness was seen among 0.9 per cent female). Twenty nine per cent were overweight (BMI 25-29.9) and 4.0 per cent were obese (BMI >30). It is a cause of concern, with regard to higher propensity of Indians in general and people of Kerala particularly to develop lifestyle diseases. 3.2 Skinfold Measurements of the Selected

\section{Subjects as per their BMI}

The skinfold measurements are simpler and less expensive methods of estimating body composition. In the present study skinfold measurement was taken at four different sites namely, triceps, biceps, subscapular and suprailiac.

\subsubsection{Skinfold at Triceps (TSF)}

Vertical fold was measured at the posterior midline of the upper arm, halfway between the tip of the shoulder and tip of the elbow, the elbow remaining in an extended and relaxed position using Harpenden's Calipers. Results obtained are given in Table 4

Female underweight adults had minimum mean value of $8.6 \mathrm{~mm}$ followed by $15.5 \mathrm{~mm}$ in normal and $27.5 \mathrm{~mm}$ in overweight subjects. Subjects had a higher TSF in the late adulthood (30-60 yrs) compared to early adulthood. As observed in the present study, Khayyam et al.[8] observed significant difference between the TSF values of adults in early to late adulthood. Overweight subjects had TSF higher than NHANES [9] reference value. This may be attributed to the higher body fat observed in Indian population. Yap et al. [10] studied the body fat percentage among the three different ethnic groups Chinese, Malays and Indians. Among them, Indians had the highest BF per cent and Chinese the lowest for the same BMI. These differences could be ascribed to differences in the ethnic influences on body composition pattern. A study reported by Kapoor et al. [11] showed that TSF did not to have any correlation with height but there was good positive correlation with body mass index among adolescents in New Delhi. Hence it may be regarded as a reliable indicator of obesity.

\subsubsection{Skinfold at Biceps of the Selected Subjects}

Biceps Skinfold Thickness (BSF) was measured as the thickness of a vertical fold on front of the upper left arm and above the centre of cubital fossa, to the nearest $0.1 \mathrm{~mm}$. The average of two readings was taken and presented In table 5. The mean biceps skinfold values of $4.8 \mathrm{~mm}$ for underweight, $11.3 \mathrm{~mm}$ for normal weight and $22.6 \mathrm{~mm}$ for overweight subjects were observed in the present study. The mean biceps skinfold measurements increased from underweight to normal and overweight subjects.

\subsubsection{Subscapular Skinfold Measurements of the Selected Subjects}

Subscapular skinfold site is at the bottom point of shoulder blade and is one of the common locations used for the assessment of body fat using skinfold caliper. Table 6 gives the data on sub scapular skinfold measurement as per BMI. 
Table 3 shows the Body Mass Index of the selected subjects.

Table 3. Body mass index of the subjects

\begin{tabular}{|c|c|c|}
\hline $\begin{array}{c}\text { Body Mass Index of the } \\
\text { subjects }\left(\mathrm{Kg} / \mathrm{m}^{2}\right)\end{array}$ & Number & Per cent \\
\hline \multicolumn{3}{|l|}{ Underweight $(<18.5)$} \\
\hline$<16$ (Severe underweight) & 11 & 0.9 \\
\hline 16-16.9 (Moderate underweight) & 40 & 3.1 \\
\hline 17-18.4 (Mild underweight) & 98 & 7.6 \\
\hline Total & 149 & 11.6 \\
\hline _Normal (18.5-24.9) & 714 & 55.4 \\
\hline Overweight/Pre obese $(<18.5-24.9)$ & 373 & 29.0 \\
\hline \multicolumn{3}{|l|}{ Obese $(>30)$} \\
\hline 30-34.9 (Obesity grade I) & 44 & 3.4 \\
\hline 35-39.9 (Obesity grade II) & 8 & 0.6 \\
\hline$\geq 40$ (Obesity grade III) & 0 & 0 \\
\hline Total & 52 & 4.0 \\
\hline Grand total & 1288 & 100 \\
\hline
\end{tabular}

Table 4. Triceps skinfold ( $\mathrm{mm}$ ) of the selected subjects as per BMI status

\begin{tabular}{|c|c|c|c|c|}
\hline \multirow{2}{*}{$\begin{array}{l}\text { Age group } \\
\text { ( Yrs) }\end{array}$} & \multirow{2}{*}{$\begin{array}{l}{ }^{*} \operatorname{Ref} \\
(\mathrm{mm})\end{array}$} & & & \multirow[b]{2}{*}{ OW } \\
\hline & & UW & $\mathbf{N}$ & \\
\hline $18-29$ & \multirow{3}{*}{24.1} & $8.0 \pm 2.4$ & $14.5 \pm 5.5$ & $25.1 \pm 9.2$ \\
\hline $30-60$ & & $9.2 \pm 2.6$ & $16.6 \pm 6.9$ & $29.9 \pm 9.5$ \\
\hline Mean & & $8.6 \pm 2.5$ & $15.5 \pm 6.2$ & $27.5 \pm 9.3$ \\
\hline
\end{tabular}

${ }^{\star}$ Reference value ${ }^{\star}$ NHANES [9] .

Table 5. ${ }^{\star}$ Biceps skinfold measurements $(\mathrm{mm})$ of the selected subjects as per BMI status

\begin{tabular}{|c|c|c|c|}
\hline \multirow{2}{*}{$\begin{array}{l}\text { Age group } \\
\text { ( Yrs) }\end{array}$} & & & \\
\hline & UW & $\mathrm{N}$ & ow \\
\hline $18-29$ & $4.7 \pm 1.7$ & $12.1 \pm 4.3$ & $20.3 \pm 7.8$ \\
\hline $30-60$ & $5.0 \pm 1.6$ & $10.6 \pm 5.3$ & $24.9 \pm 8.1$ \\
\hline Mean & $4.8 \pm 1.6$ & $11.3 \pm 4.8$ & $22.6 \pm 7.9$ \\
\hline
\end{tabular}

UW-Under weight OW-Over Weight N-Normal Weight ${ }^{*}$ reference value not available
Table 6. Subscapular measurements $(\mathrm{mm})$ of the selected subjects as per BMI status

\begin{tabular}{|c|c|c|c|c|}
\hline \multirow{2}{*}{$\begin{array}{c}\text { Age group } \\
\text { ( Yrs) }\end{array}$} & \multirow{2}{*}{${ }^{\star} \operatorname{Ref}(\mathrm{mm})$} & \multicolumn{3}{|c|}{ Body mass index } \\
\hline & & UW & $\mathbf{N}$ & ow \\
\hline $18-29$ & \multirow{3}{*}{20.8} & $9.4 \pm 2.1$ & $18.3 \pm 5.4$ & $27.2 \pm 10.5$ \\
\hline $30-60$ & & $9.6 \pm 1.9$ & $20.8 \pm 7.9$ & $29.4 \pm 9.3$ \\
\hline Mean & & $9.5 \pm 2.0$ & $19.5 \pm 6.6$ & $28.3 \pm 9.9$ \\
\hline
\end{tabular}

* NHANES [9] .

Measurement of subscapular skinfold varied from $9.5 \mathrm{~mm}$ in underweight subjects $19.5 \mathrm{~mm}$ in normal to $28.3 \mathrm{~mm}$ in overweight subjects. Subscapular measurements were much higher in later adulthood compared to younger adulthood in the sub groups.

\subsubsection{Suprailiac Measurements of the Selected Subjects}

Suprailiac known as supraspinale skinfold site is one of the common locations used for the assessment of body fat using skinfold caliper. Table 7 gives the mean suprailiac skinfold thickness in males and females during early and late adulthood.

Table 7. Suprailiac measurements $(\mathrm{mm})$ of the selected subjects as per BMI status.

\begin{tabular}{|c|c|c|c|c|}
\hline \multirow{2}{*}{ Age group } & \multirow{2}{*}{${ }^{\star} \operatorname{Ref}(\mathrm{mm})$} & & & \\
\hline & & UW & $\mathbf{N}$ & OW \\
\hline $18-29$ & \multirow{3}{*}{24.1} & $10.0 \pm 2.5$ & $22.2 \pm 7.1$ & $36.0 \pm 12.6$ \\
\hline $30-60$ & & $9.5 \pm 2.9$ & $26.1 \pm 9.6$ & $42.4 \pm 12.8$ \\
\hline Mean & & $9.7 \pm 2.7$ & $24.1 \pm 8.3$ & $39.2 \pm 12.7$ \\
\hline
\end{tabular}

* NHANES [9] .

Suprailiac skinfold thickness was $9.7 \mathrm{~mm}, 24.1 \mathrm{~mm}$ and $39.2 \mathrm{~mm}$ for underweight, normal and overweight subjects respectively. Mean suprailiac value increased during late adult hood except for underweight female subjects. The results of the present study are similar to observations of Matton et al. [8] and Khyyam et al. [7] who inferred that there was an increase in suprailiac values for both men and women in late adulthood.

\subsection{Per Cent Body Fat from Sum of Skinfold Measurement}


Body fat per cent of subjects determined from sum of skinfolds using Durnin Womersley equation [4] is given in Table 8.

Table 8. Per cent body fat from sum of skinfold thickness of the selected subjects as per BMI

\begin{tabular}{|c|c|c|c|c|}
\hline \multirow{2}{*}{$\begin{array}{c}\text { Age group } \\
(\text { yrs })\end{array}$} & & & & \multirow[b]{2}{*}{ 'F' value } \\
\hline & $\begin{array}{c}\text { UW } \\
(\mathrm{n}=70)\end{array}$ & $\begin{array}{c}N \\
(n=70)\end{array}$ & $\begin{array}{c}\text { OW } \\
(n=70)\end{array}$ & \\
\hline 18- 29 & $21.0 \pm 2.4$ & $30.6 \pm 3.6$ & $36.7 \pm 6.6$ & \multirow{3}{*}{$378.551^{\star *}$} \\
\hline $30-60$ & $24.6 \pm 2.7$ & $34.8 \pm 5.4$ & $41.8 \pm 4.8$ & \\
\hline Mean & $22.8 \pm 2.5$ & $32.7 \pm 4.5$ & $39.2 \pm 5.7$ & \\
\hline
\end{tabular}

${ }^{*}$ Significant $\mathrm{p}<0.01 \quad$ UW-Underweight ; N-Normal ;

OW-Overweight

Body fat per cent of underweight, normal and overweight female subjects determined from sum of skin fold were $22.8 \pm 2.5,32.7 \pm 4.5$ and $39.2 \pm 5.7$ per cent respectively. Body fat per cent was found to increase considerably during late adulthood. It is evident from the study; that even at lower BMI subjects had higher percentage of body fat. Statistical analysis showed positive association between BMI and body fat per cent determined from sum of skinfolds using Durnin Womersley equation ( $\mathrm{F}=378.551 \mathrm{p}<0.01)$.

Gibson [13] stated that, on an average the fat content of women is higher than that of men representing 26.9 per cent of the total body weight compared with 14.7 per cent for men. According to Singh et al. [14], Asians had more

\section{Conclusion}

To sum up, 44.6 per cent of the adult women population in Kochi faces burden of malnutrition in which 33.0 per cent were overweight/obese and 11.6 per cent were underweight. There was a direct proportion between BMI and per cent body fat; at higher BMI per cent body fat was also high. The national health policy emphasized the eradication of underweight in India. But the scenario was different among the subjects in the study area of Kochi Corporation, where overweight exceeded underweight which has grown to epidemic proportions. Strategies at individual level must be evolved to instill the dangers of wrong dietary habits and adopt healthy eating practices and physical activity to prevent chronic degenerative diseases associated with overweight and obesity.

\section{References}

1. Ajithkumar N., and Radhadevi D., "Health of Women in Kerala: Current Status and Emerging Issues", Working Paper No. 23, Centre for Socio-economic and Environmental Studies, p. 38, 2010.

2. WHO expert consultation. "Appropriate body-mass index for Asian populations and its implications for policy and intervention strategies". The Lancet, vol. 363, p. 157-163, 2004.

3. Indian Council of Medical Research (ICMR). Nutrient requirements and recommended dietary allowances for Indians. NIN, Hyderabad, p. 11-27, 1990.

4. Durnin J.V.G.A., and Womersley J., "Body fat assessed from total body density and its estimation from skinfold thickness: measurements on 481 men and women aged from 16 to 72 years", Br. J. Nutr., vol. 32, p. 77-97, 1974.

5. Ministry of Home Affairs, Government of India, Census, Kerala Summary. Population Totals 2001.

6. NFHS-2 National Family Health Survey, 1998-99. India Mumbai: International Institute for Population Sciences (IIPS) and ORC Macro. National Family Health Survey (NFHS-2:1998-99) India, key findings. Ministry of Health and Family Welfare, Govt. of India IIPS; 2000.

7. NFHS-1 National Family Health Survey, $(\mathrm{MCH}$ and family planning), India 1992-93. International Institute for Population Sciences (IIPS), Bombay, 1995.

8. Khayyam K. V., Khan S. Y., Khan M. Y., and Muzammil S., "Prevalence of obesity in an urban population - A Community based study". Indian Journal of the Practicing Doctor, vol. 5(5), p. 2008-11-2008-2012, 2005.

9. NHANES National Health and Nutrition Examination Survey, "2003-2006 Anthropometric reference data for children and adults: United States of America", National Health Statistics Reports. Number 10, p. 5-42, 2008.

10. Yap D. M., Schmidt G., Staveren V. W. A., Deurenberg P., "The paradox of low body mass index and high body fat percentage among Chinese, Malays and Indians in Singapore", International Journal of Obesity Related Metabolic Disorders, vol. 24(8), p. 1011-1017, 2000. 11. Kapoor G., Aneja S., Kumari S., and Mehta S.C., "Triceps skinfold thickness in adolescents". Indian. J. Med. Res., vol. 94, p. 281-285, 1991.

12. Matton L., Thomis M., Wijndaele K., Duvigneaud N., Beunen G., Claessens A. L., Vanreusel B., Philippaerts R., and Lefevre J., "Tracking of physical fitness and physical activity from youth to adulthood in females". Med. Sci. Sports. Exerc., vol. 38(6), p. 1114-1120, 2006.

13. Gibson R.S., Principles of Nutritional Assessment, 2nd Ed., Oxford University Press, New York, p. 292-293, 2005. 
14. Singh K. D., Dhillon J. K., Arora A., Gill B. S., "Receiver operating characteristic curve analysis of BMI and per cent body fat in Type 2 diabetics of Punjab". Indian J. Physiol. Pharmacol., vol. 48(1), p. 73-80, 2004. 